
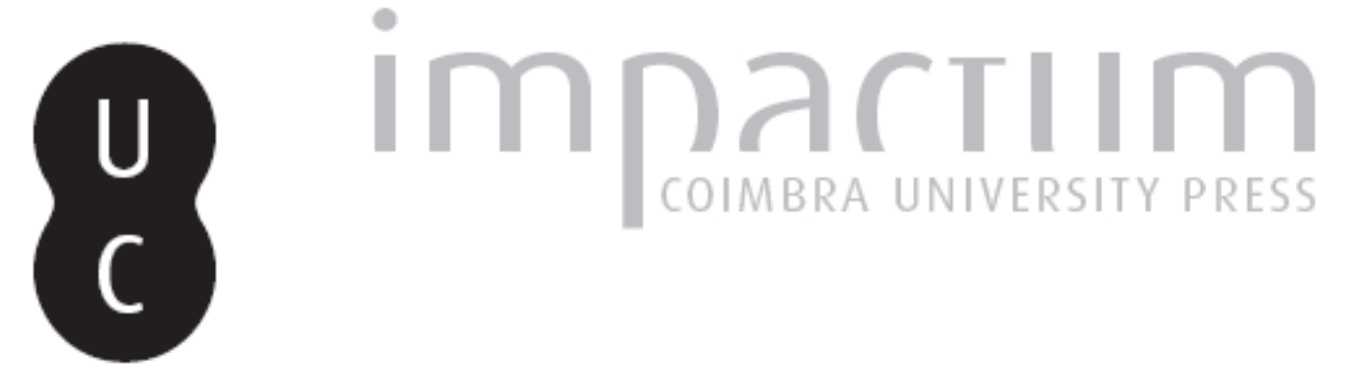

Equidade: a chave para explicar os tarifários de água em Portugal?

Autor(es): $\quad$ Martins, Rita; Quintal, Carlota; Pimentel, Ana Bela

Publicado por: Faculdade de Economia da Universidade de Coimbra

URL persistente:

URI:http://hdl.handle.net/10316.2/25212

DOI:

DOI:http://dx.doi.org/10.14195/2183-203X_29_3

Accessed : $\quad$ 26-Apr-2023 12:52:34

A navegação consulta e descarregamento dos títulos inseridos nas Bibliotecas Digitais UC Digitalis, UC Pombalina e UC Impactum, pressupõem a aceitação plena e sem reservas dos Termos e Condições de Uso destas Bibliotecas Digitais, disponíveis em https://digitalis.uc.pt/pt-pt/termos.

Conforme exposto nos referidos Termos e Condições de Uso, o descarregamento de títulos de acesso restrito requer uma licença válida de autorização devendo o utilizador aceder ao(s) documento(s) a partir de um endereço de IP da instituição detentora da supramencionada licença.

Ao utilizador é apenas permitido o descarregamento para uso pessoal, pelo que o emprego do(s) título(s) descarregado(s) para outro fim, designadamente comercial, carece de autorização do respetivo autor ou editor da obra.

Na medida em que todas as obras da UC Digitalis se encontram protegidas pelo Código do Direito de Autor e Direitos Conexos e demais legislação aplicável, toda a cópia, parcial ou total, deste documento, nos casos em que é legalmente admitida, deverá conter ou fazer-se acompanhar por este aviso.

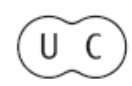




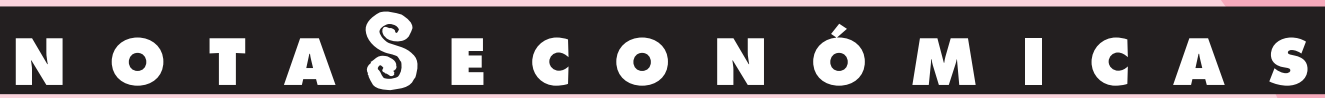

ANA BELA NUNES TOMÁS CABREIRA: UM ECONOMISTA POLIITICO NUM PAÍS DE "FINANÇAS AVARIADAS"

\begin{abstract}
RAQUEL VALE MENDES GENDER WAGE DIFFERENTIALS AND OCCUPATIONAL DISTRIBUTION
\end{abstract}
RITA MARTINS /

CARLOTA QUINTAL / ANA PIMENTEL
EQUIDADE: A CHAVE PARA EXPLICAR OS TARIFÁRIOS DE ÁGUA EM PORTUGAL

DOUTORAMENTO HONORIS CAUSA DO EMBAIXADOR JUAN SOMAVIA, DIRECTOR DA OIT 


\section{Equidade: a chave para explicar os tarifários de água em Portugal?*}

Rita Martins / Carlota Quintal / Ana Pimentel FEUC, GEMF/FEUC, CEIS/FEUC

resumo

Em face de uma lacuna da literatura relacionada com a abordagem da equidade no sector da água, o objectivo do presente artigo é averiguar se os tarifários de serviços de abastecimento de água nos municípios portugueses incorporam preocupações de equidade entre classes de rendimento.

Procede-se, para tanto, à determinação de quantidades mínimas essenciais de água e ao seu confronto com o limite do primeiro escalão de consumo em cada concelho. Numa etapa seguinte, por intermédio da elaboração de rankings relativos aos encargos inerentes ao consumo dessas quantidades essenciais e aos rendimentos médios da família representativa de cada concelho, em conjunto com metodologias baseadas no traçado de curvas de concentração e no cálculo de índices de concentração, conclui-se que existe regressividade nos pagamentos, ou seja, iniquidade favorável às famílias (concelhos) de rendimentos mais elevados. résumé / abstract

Vu le vide dans la littérature concernant l'analyse de l'équité dans le secteur des eaux, le présent travail va essayer de savoir si les tarifs des services d'approvisionnement en eau des municipalités portugaises reflètent des soucis d'équité pour les différentes catégories de revenu.

On essaie d'abord d'établir les minima essentiels en eau pour les confronter avec la limite fixée pour l'échelon le plus bas de consommation d'eau dans les différentes municipalités. Ensuite, après avoir classé les charges de la consommation d'eau et les revenus moyens du ménage représentatif pour chaque municipalité, on utilise des courbes et des indices de concentration pour conclure que les payements sont régressifs, c'est-à-dire qu'il y a une injustice en matière de tarifs qui favorise les ménages à revenus plus élevés.

Given the gap in the literature regarding equity analyses in the water industry, the objective of this paper is to evaluate whether or not income-related equity considerations are embodied in water supply tariffs, in the Portuguese municipalities.

Essential minimum quantities of water are determined for representative households, which are then compared with the first tariff block's upper limit applying on their respective municipalities. Next, representative households are ranked by costs underlying minimum quantities and by income. The methodology used in this paper is also based on concentration curves and indexes. We conclude that payments of water bills are regressive, or, in other words, there is inequity favourable to the better-off representative households. 
Na procura de respostas para diversos constrangimentos de ordem ambiental, institucional, financeira, e mesmo social, com que o sector das águas se defronta, face à definição de metas exigentes decorrentes de legislação nacional e comunitária, a literatura económica tem-se debruçado sobre a definição de políticas tarifárias capazes de acomodar restrições de vária natureza. Existe mesmo algum consenso de que as tarifas podem ser utilizadas como veículo para a prossecução de um conjunto diversificado de objectivos. No entanto, o enfoque tem estado sobretudo direccionado para questões de eficiência económica, deixando a abordagem de equidade pouco explorada.

Tratando-se, como é frequente à escala internacional e regra no plano nacional, da prática de tarifários por blocos com preços crescentes, a equidade e a sustentabilidade do recurso água surgem à cabeça como os objectivos mais habitualmente apontados em defesa destes esquemas tarifários.

Pretendendo-se contribuir para o preenchimento de uma lacuna da literatura, relacionada com a abordagem da equidade no sector da água, o objectivo do presente artigo é averiguar se os tarifários referentes a serviços de abastecimento de água nos municípios portugueses incorporam preocupações de equidade, mais concretamente, de equidade entre classes de rendimento, tal como definida pela OCDE.

Para tanto, procede-se, em primeiro lugar, ao confronto das quantidades mínimas essenciais de consumo de água por família com os limites do primeiro escalão de consumo. Numa etapa seguinte, por intermédio da elaboração de rankings relativos aos encargos inerentes ao consumo dessas quantidades essenciais e aos rendimentos médios da família representativa de cada concelho avalia-se se os encargos suportados estão relacionados com a capacidade de pagar.

Finalmente, e por não existirem propriamente sugestões da literatura para o tratamento da temática da equidade no sector em estudo, socorre-se de metodologias aplicadas ao sector da saúde (este, igualmente como o da água, considerado um serviço de interesse geral). Estas metodologias baseiam-se em curvas de concentração e no cálculo de índices de concentração, para verificar se a relação entre os encargos com o serviço de abastecimento de água e a capacidade de pagamento das famílias é proporcional, progressiva ou regressiva.

O presente trabalho encontra-se organizado da seguinte forma. Na segunda Secção procura-se caracterizar, sumariamente, os tarifários relativos a serviços de abastecimento de água em vigor nos concelhos portugueses. Na terceira Secção procede-se ao enquadramento conceptual da equidade e da sua promoção via tarifas. Na quarta Secção expõe-se a metodologia e os dados utilizados, procedendo-se à sua análise e discussão na quinta Secção. A última Secção destina-se às conclusões.

\section{Tarifas de serviços de abastecimento de água em Portugal}

O sector das águas ou sector de serviços de águas compreende as actividades de abastecimento de água (AA) às populações, urbanas e rurais, e às actividades associadas, como os serviços, o comércio e a pequena indústria inserida na malha urbana; a drenagem e o tratamento (saneamento) de águas residuais (SAR) urbanas, que incluem as águas residuais de origem doméstica, industrial e pluvial. No presente trabalho, considera-se apenas a vertente do AA ao sector residencial, sendo o enfoque colocado na vertente em "baixa" do sector. Esta abrange, de forma simplificada, a distribuição, ao passo que a "alta" compreende as actividades a montante da distribuição.

Em cada concelho há um único operador, na gíria do sector, entidade gestora $(E G)$, pelo que a estrutura de mercado pode ser caracterizada pela existência de múltiplos monopólios locais, o 
que não permite uma formação concorrencial de preços. Em termos do número de operadores predominam as entidades com gestão directa (serviços municipais, serviços municipalizados e associações de municípios). Igualmente expressivo é o número de EG que assumem uma gestão delegada (empresa municipal ou intermunicipal). Finalmente, um terceiro tipo de entidades presentes no serviço de abastecimento de água em baixa engloba as concessionárias municipais ou multimunicipais (IRAR, 2008).

Face à maneira como o sector das águas se encontra organizado em Portugal, coexistem diferentes formas de definição e aprovação das tarifas. Em termos resumidos, tratando-se de entidades da administração local autárquica, os tarifários são aprovados pelas respectivas Assembleias Municipais, ao passo que quando se trata de concessões municipais as tarifas são fixadas no contrato, o qual estabelece também a fórmula de revisão das mesmas.

De forma simplificada pode-se considerar que a factura de água suportada pelo segmento residencial é formada essencialmente por duas componentes principais: um encargo fixo ( $E F$ ) e uma componente dependente da quantidade de água consumida, correspondente ao encargo variável ( $E V$ ), também reconhecido como parte volumétrica.

A estrutura tarifária predominante no que se refere à parte variável da factura é composta por diversos escalões, também designados blocos de consumo. Em relação a esta componente, e para o sector doméstico, praticam-se tarifas multipartidas, com preços crescentes por escalões de consumo (TPC). A regra para a determinação do valor da factura consiste em aplicar preços sucessivamente crescentes a parcelas, relativamente a quantidades consumidas, também elas cada vez mais elevadas. Menos frequentes são os tarifários, onde apenas um preço, dependente da quantidade de água consumida, é aplicado a todos os metros cúbicos de água consumidos. Ou seja, toda a quantidade consumida é paga ao preço do escalão mais alto atingido.

É importante salientar ainda que, independentemente do esquema tarifário privilegiado, praticamente não existem tarifários iguais entre municípios. De facto, mesmo nos casos em que há coincidência em termos da estrutura dos blocos (número e dimensão dos mesmos), encontram-se diferenças entre preços praticados para cada bloco.

\section{Equidade e tarifação}

\subsection{Dimensões da equidade}

De acordo com a OCDE (OECD, 2003: 21), podem considerar-se quatro dimensões básicas da equidade no domínio do sector da água: equidade entre classes de rendimento; equidade entre tipos de consumidor; equidade entre regiões; e equidade intergeracional.

Para garantir equidade entre classes de rendimento deve ser possibilitada às classes sociais com mais baixos rendimentos a aquisição de água potável, pelo menos para satisfazer as necessidades básicas, a um preço que não estrangule a sua restrição orçamental. Trata-se de uma dimensão que considera solidariedade entre ricos e pobres.

Em relação à equidade entre tipos de consumidor, o que interessa garantir é que os consumidores que adquirem maiores quantidades de água deverão pagar tarifas mais altas.

Por seu turno, o respeito pela equidade entre regiões preconiza a solidariedade entre regiões, tendo em conta os seus recursos naturais e o seu desenvolvimento económico. Uma vez que as dotações naturais de água são diferentes de região para região, naquelas onde a água é mais escassa, o seu preço tenderá a ser mais elevado, e tratando-se de uma região menos desenvolvida deverá haver solidariedade entre regiões.

Por fim, para alcançar a equidade intergeracional, as gerações presentes devem utilizar o recurso água de forma sustentável, de modo a que as gerações futuras possam usufruir deste recurso essencial. Esta dimensão da equidade está muito ligada à sustentabilidade ambiental e do próprio recurso. Pretende-se que o nível de consumo presente não diminua a hipótese das 
gerações futuras beneficiarem do recurso água e de uma qualidade ambiental idêntica à legada pelas gerações actuais e passadas.

As duas abordagens para analisar a equidade na tarifação no sector da água, adoptadas neste trabalho, estão muito próximas da primeira dimensão de equidade acima descrita. Na definição da OCDE, são destacados dois aspectos fundamentais: a satisfação de necessidades básicas e a associação entre as despesas da água e o rendimento disponível.

O primeiro destes aspectos pode ser interpretado como a adaptação ao sector da água de um conceito de justiça distributiva mais amplo que é o do mínimo decente (decent minimum). Este conceito surge na sequência das teorias mais liberais, correspondendo o mínimo decente a uma quantidade de cujo acesso ninguém deve ser excluído. Ou seja, segundo este conceito, deve ser garantida a satisfação das necessidades humanas básicas, o que poderia não ser conseguido apenas com o livre funcionamento do mercado (Buchanan, 1985).

Relativamente à associação entre despesa e rendimento, encontra-se algumas justificações para esta posição em discussões no contexto do sector da saúde (Wagstaff e van Doorslaer, 2000). A preocupação principal é dissociar os pagamentos da utilização. Isto porque, por um lado, existe o receio de que os pagamentos afectem a capacidade de consumir algo que é considerado essencial; e, por outro lado, sendo uma despesa relativa à satisfação de necessidades básicas, trata-se de uma despesa involuntária, devendo por isso existir uma solidariedade da comunidade face a cada um dos seus elementos.

\subsection{Promoção da equidade via tarifação}

Esquemas tarifários como as TPC podem ser utilizados para promover objectivos de equidade.

No âmbito da equidade entre classes de rendimento, e no que diz respeito às quantidades essenciais, assume particular relevância o primeiro escalão de consumo, cujo preço é o mais baixo. Este bloco pode, assim, ser encarado, conforme sugerido pela literatura, como aquele que deve acomodar as quantidades de água que garantem a satisfação das necessidades mínimas essenciais, como a alimentação e a higiene, na linha de argumentação de (Bolland e Whittington, 2000).

Para além deste aspecto, a justificação de TPC devido a preocupações de equidade assenta no pressuposto de que o consumo de água está directamente relacionado com o rendimento. A ideia é, por intermédio deste esquema de tarifas, fazer com que as famílias mais ricas subsidiem o consumo das famílias mais pobres. Neste sentido, o encargo associado ao consumo de água deveria ter uma relação directa com o rendimento disponível.

Naturalmente, existem diversos outros objectivos deste tipo de tarifação, como os de conservação e de utilização sustentável do recurso água (OECD, 2009; Griffin, 2009; Monteiro, 2005). A justificação para a prática de TPC é neste âmbito desencorajar, penalizando via preço, os consumos excessivos. Por outro lado, em contextos de monopólio natural, a adequação de TBC a objectivos de eficiência pode ser questionável, na medida em que para acompanhar custos marginais decrescentes deveriam ser adoptadas tarifas por blocos com preços igualmente decrescentes (Hirshleifer et al., 1960; Arbués et al., 2003).

\section{Metodologia e Dados}

\subsection{Introdução}

Nesta Secção pretende-se explicar a metodologia definida e aplicada para investigar se os esquemas tarifários aplicados ao serviço de abastecimento de água em Portugal incorporam preocupações de equidade.

A abordagem passa pela quantificação de quantidades mínimas essenciais ( $Q M E)$ e pelo confronto dessas quantidades com a dimensão do primeiro escalão de consumo, investigando- 
-se a racionalidade na definição desse escalão. Este procedimento permite averiguar se existe alguma relação, nos vários concelhos portugueses, entre a dimensão desse primeiro escalão e as quantidades mínimas essenciais que, pela sua natureza, devem ser acessíveis a todos os cidadãos a um preço comportável. Posteriormente, procede-se a uma análise comparativa entre os encargos associados ao consumo dessas quantidades essenciais e o rendimento médio da família representativa de cada concelho. Avalia-se assim a existência ou não de proporcionalidade dos encargos face à capacidade de pagar das famílias. Aplica-se esta última análise ainda ao caso de um consumo anual de $60 \mathrm{~m}^{3}$, equivalente a um consumo mensal de $5 \mathrm{~m}^{3}$, quantidade de referência definida pelo Instituto Regulador de Águas e Resíduos (IRAR).

Em virtude de o estudo se basear em dados seccionais, por município, considera-se como unidade de observação a família típica por concelho.

\subsection{QME e primeiro escalão de consumo}

Como ponto de partida, consideram-se os valores definidos pela Organização Mundial de Saúde para os consumos considerados mínimos, de aproximadamente 40 litros por dia e por pessoa, como referência para satisfazer as necessidades consideradas essenciais. Assim, fazendo a correspondente equivalência em metros cúbicos (medida adoptada no consumo de água), $0,04 \mathrm{~m}^{3}$ é considerada a QME por pessoa e por dia, a que todos os cidadãos deveriam ter acesso a um preço comportável.

Uma vez que a unidade de observação relevante é a família, torna-se necessário o cálculo prévio da dimensão média do agregado familiar $(D M A)$. A $D M A$ obtém-se como o rácio entre a população residente (INE, 2009), e o número total de famílias clássicas de cada concelho.

As $Q M E$, em metros cúbicos, para uma família típica, para cada município, obtêm-se conforme expresso na equação (1).

$$
Q M E=0,04{ }^{*} D M A * 30
$$

A multiplicação por 30 deve-se ao facto de os tarifários serem aplicados aos consumos mensais.

\subsection{Encargos e rendimentos}

Numa etapa seguinte, procede-se ao cálculo do encargo associado à $Q M E(E Q M E)$ por município. Este encargo engloba a componente variável da factura e uma componente fixa. A primeira depende não só das estruturas tarifárias (preços e dimensão dos escalões) praticadas pelas EG, bem como da própria QME, que varia entre os municípios, de acordo com a dimensão média do agregado de cada concelho. A componente fixa, ou tarifa de disponibilidade como é habitualmente designada, é também diferente consoante os vários concelhos.

A equação (2) mostra como se calcula o $E Q M E$, ignorando outras rubricas da factura como impostos e taxas, e admitindo ou que a $Q M E$ fica integralmente coberta pelo primeiro escalão, ou que vigora um tarifário progressivo integral. Neste último caso $p$ será o preço do escalão mais alto atingido enquanto que no primeiro caso $p$ diz respeito ao preço do primeiro escalão.

$$
E Q M E=E F+Q M E^{*} p
$$

em que EF corresponde ao encargo fixo (na verdade dependente do calibre do contador, tendo sido considerado um calibre de $15 \mathrm{~mm}$, o mais usualmente considerado tratando-se de consumidores domésticos) cobrado em cada concelho. A segunda parcela do segundo membro da equação (2) corresponde à componente volumétrica do consumo em cada concelho. 
Nos casos em que a QME ultrapasse o primeiro escalão, e vigorem TPC então a equação (2) deve ser adaptada, repartindo a QME pelo escalóes abrangidos e aplicando às respectivas parcelas os preços dos vários escalões atingidos. Tratando-se, por exemplo, de uma situação em que a QME atinge o segundo escalão a equação (2) deve ser adaptada conforme expresso pela equação (2.1).

$$
E Q M E=E F+q_{1}{ }^{*} p_{1}+\left(Q M E-q_{1}\right){ }^{*} p_{2}
$$

em que $q_{1}$ corresponde ao limite superior do primeiro escalão e $p_{1}$ e $p_{2}$ correspondem aos preços dos blocos 1 e 2 , respectivamente.

Todos os dados (encargo fixo, número dimensão dos escalões e respectivos preços) necessários aos cálculos dos EQME, foram disponibilizados pelo IRAR e correspondem aos esquemas tarifários praticados por cada operador em cada município em 2007.

Para estabelecer uma comparação entre o EQME e o rendimento por agregado, procede-se previamente ao cálculo do rendimento por agregado com base em dados sobre o Imposto sobre o Rendimento de Pessoas Singulares (IRS) líquido de 2003, da Direcção Geral de Finanças, e atendendo à dimensão populacional de cada concelho (INE, 2009) e respectiva DMA.

Posteriormente, organiza-se a informação por concelho em termos de rendimento por agregado e em termos do EQME sob a forma de rankings, em ambos os casos por ordem decrescente dos valores de cada série. A partir daqui torna-se possível a comparação do posicionamento da família típica de cada concelho nas duas escalas de ordenação.

\subsection{Curvas e Índices de Concentração}

As medidas de concentração são geralmente utilizadas para fazer uma análise da distribuição do rendimento, podendo, no entanto, ser utilizadas para medir o grau de concentração de qualquer distribuição estatística. Assim, pode medir-se também o grau de concentração da distribuição das despesas com o consumo de água. A curva de concentração do rendimento é a conhecida curva de Lorenz, sendo esta curva formada pela união dos pontos bidimensionais onde no eixo dos $x x$ temos a percentagem acumulada da população ordenada pelo rendimento e no eixo dos yy temos a percentagem acumulada do rendimento. Analogamente, no caso da curva de concentração das despesas com o consumo de água, no eixo dos $x x$ temos a percentagem acumulada da população ordenada pelo rendimento e no eixo dos yy temos a percentagem acumulada dos encargos com o consumo de água.

As desigualdades são tanto maiores quanto mais as curvas de concentração se afastam da diagonal (linha de igual distribuição). Contudo, do ponto de vista da equidade, o importante é analisar em que medida os encargos da factura do serviço de abastecimento de água estão relacionados com a capacidade de pagamento e verificar se essa relação é proporcional, progressiva ou até mesmo regressiva. Isto é, o que nos interessa é comparar a curva de concentração das despesas com o consumo de água com a curva de Lorenz.

Há proporcionalidade nos pagamentos se as duas curvas de concentração coincidem; regressividade se a curva dos encargos com o consumo de água se situa acima da curva de Lorenz (significando isto que os agregados com menor rendimento médio pagam proporcionalmente mais do que os agregados com maior rendimento) e progressividade na situação inversa.

Neste estudo, considera-se a curva dos encargos com a quantidade mínima essencial, bem como a curva dos encargos inerente ao consumo anual de $60 \mathrm{~m}^{3}$. O método de cálculo do EQME foi já explicado na secção anterior e o encargo mensal, por município, associado ao consumo anual de $60 \mathrm{~m}^{3}$ foi directamente disponibilizado pelo IRAR. Note-se que o eixo dos $x x$ é comum a todas as curvas e neste eixo está representada a percentagem acumulada da 
população residente em cada concelho, face ao total do país. Dado que se trabalha com a família representativa de cada concelho, o peso da população de cada concelho corresponde a 1/308. As famílias são ordenadas pelo seu rendimento médio, do agregado mais pobre para o mais rico. O rendimento por agregado que se utiliza nesta análise é o mesmo que se calculou para as análises anteriormente expostas.

A partir de cada uma das curvas de concentração é possível calcular um índice de concentração que é igual a duas vezes a área de concentração (área entre a respectiva curva e a diagonal). 0 índice de concentração permite quantificar o grau de desigualdade na distribuição da variável em causa. No entanto e como referido anteriormente, do ponto de vista da equidade, o relevante é comparar a distribuição do rendimento com a distribuição dos encargos. Assim, em termos de quantificação, o que interessa é medir os desvios de proporcionalidade, ou seja, comparar o índice de concentração dos encargos $\left(C_{E}\right)$ com o índice de concentração do rendimento $(G)$, este último identificado na literatura económica como coeficiente de Gini. O papel do índice de Kakwani $\left(\Pi_{K}\right)$, também conhecido por índice de progressividade, é precisamente quantificar a diferença entre aqueles dois índices:

$$
\Pi_{k}=C E-G
$$

$\Pi_{K}$ situa-se entre o valor negativo de dois (-2) e um (1). Se as duas curvas de concentração coincidem, $C_{E}=G$ e $\Pi_{K}$ é nulo; se há uma maior concentração do rendimento $\left(C_{E}<G\right)$, pelo que $\Pi_{K}$ é negativo; se a curva dos encargos se situa abaixo da curva!de Lorenz ( $\left.C_{E}>G\right), \Pi_{K}$ é positivo. Assim, se o índice de Kakwani é zero podemos concluir que há proporcionalidade nos pagamentos; se é negativo, que há regressividade; e se é positivo, que há progressividade.

O índice de Kakwani pode ser calculado através de uma regressão linear, conforme metodologia proposta por Kakwani et al. (1997):

$$
2 \sigma_{R}^{2}\left[\frac{E_{i}}{\eta}-\frac{Y_{i}}{\mu}\right]=\alpha+\beta R_{i}+\varepsilon_{i}
$$

em que $\sigma_{R}^{2}$ representa a variância de $R_{i}$; o $E_{i}$ representa os encargos com a $Q M E$ ou com o consumo dos $60 \mathrm{~m}^{3}$ de água, do agregado $i ; \eta$ é a média desses encargos; $Y_{i}$ representa os ren\%imentos do agregado $i$ e $\mu$ é a sua média; $R_{i}$ é a posição fraccionária na hierarquia da distribuição do rendimento, do agregado $i ; \varepsilon_{i}$ representa os erros de especificação do modelo. Nesta regressão, a estimativa do coeficiente $\beta$ é o índice de Kakwani. Calcula-se o índice quer para os encargos com a QME quer para os encargos com o consumo dos $60 \mathrm{~m}^{3}$ de água, através do método dos mínimos quadrados usuais (OLS).

\section{Análise e discussão dos resultados}

O Quadro 1 apresenta informação estatística sobre a quantidade mínima essencial e sobre a dimensão média do agregado.

\begin{tabular}{l|ccccc}
\multicolumn{6}{l}{ Quadro 1 - EQME e DMA: Estatísticas descritivas } \\
\hline & Média & Desvio Padrão & Máximo & Mínimo \\
\hline$D M A$ & 2,791 & 0,285 & 3,848 & 2,231 \\
\hline QME & 3,350 & 0,341 & 4,618 & 2,677 \\
\hline
\end{tabular}


Conforme é visível, ambas as séries não apresentam grande variabilidade. Este resultado é compreensível em virtude da $Q M E$ depender da $D M A$, a qual, por se tratar de uma média, elimina a variabilidade intra-municipal.

Do confronto entre as quantidades mínimas essenciais com os limites do primeiro escalão, município a município, verifica-se que 36 dos 308 concelhos não abrange totalmente a QME no primeiro escalão de consumo, contrariando o que seria de esperar do ponto de vista do acesso às quantidades que garantem a satisfação de necessidades básicas. A regra, todavia, é o limite superior do primeiro escalão ser sempre mais elevado do que a QME. Ou seja, não parece haver uma intenção de subsidiar (através do primeiro escalão, com o preço mais baixo) apenas as quantidades essenciais de água.

Deve realçar-se, no entanto, que estes cálculos se baseiam na dimensão média do agregado familiar. Assim, para garantir que famílias mais numerosas tenham também acesso às quantidades mínimas essenciais dentro do primeiro bloco de consumo, é necessário expandir esse bloco, o que acaba por beneficiar em termos de preço subsidiado as famílias mais pequenas. Na verdade, ao repetirmos os cálculos da QME para o caso das famílias numerosas (segundo a Associação Portuguesa de Famílias Numerosas, constituídas por um casal e três ou mais filhos), deparamo-nos com um cenário fortemente penalizador para estas famílias, verificando-se que apenas 51 concelhos abrangem no primeiro escalão de consumo a quantidade mínima necessária para esse padrão familiar.

No que concerne aos encargos, o Quadro 2 contém informação sobre os encargos fixo e variável correspondentes à $Q M E$.

\begin{tabular}{|c|c|c|c|c|c|}
\hline & & Média & Desvio Padrão & Máximo & Mínimo \\
\hline \multirow{2}{*}{$\begin{array}{c}E Q M E \\
(€ \text { de 2007) }\end{array}$} & $E F$ & 1,99 & 1,32 & 7,33 & 0,00 \\
\hline & EV & 1,30 & 0,58 & 4,47 & 0,00 \\
\hline
\end{tabular}

Da sua observação destaca-se a grande disparidade de valores, ao contrário do observado no Quadro 1. A variabilidade encontrada deve-se à diversidade de tarifários em vigor nos municípios portugueses. O valor mínimo do EF explica-se pelo facto de existirem casos (em cerca de $10 \%$ dos municípios) onde não é cobrada qualquer tarifa de disponibilidade. Quanto ao valor zero relativo ao $E V$, a sua justificação prende-se com a ausência de cobrança de uma componente volumétrica, correspondendo a tarifa a um valor fixo mensal (o que se verifica em dois concelhos apenas).

Relativamente aos rankings do rendimento por agregado e do EQME, e tomando como referência os quartis, são numerosas as disparidades encontradas. Por exemplo, dez concelhos com maior EQME estão posicionados no último quartil do ranking do rendimento, ou seja, dez dos concelhos mais pobres em termos de rendimento por agregado, têm dos maiores encargos com a QME. De igual modo contraditório, encontramos 19 concelhos que se encontram no terceiro e quarto quartis do ranking do EQME mas que no entanto são concelhos pertencentes ao primeiro quartil do ranking de rendimento.

O Quadro 3 ilustra alguns destes casos. Neste Quadro, figuram os concelhos que ocupam a primeira posição em cada quartil do EQME. Para cada quartil seleccionaram-se ainda os concelhos que apresentam maiores diferenças relativamente às posições ocupadas nos dois rankings. 


\begin{tabular}{c|lc}
\hline $\begin{array}{c}\text { Quadro 3 - Posição ocupada por alguns concelhos nos rankings do EQME e do rendimento } \\
\begin{array}{c}\text { Posição do concelho } \\
\text { no ranking do EQME }\end{array}\end{array}$ & $\begin{array}{c}\text { Cosição do concelho } \\
\text { no ranking do rendimento }\end{array}$ \\
\hline $1^{\circ}$ & Póvoa de Varzim & $252^{\circ}$ \\
\hline $22^{\circ}$ & Sabugal & $289^{\circ}$ \\
\hline $53^{\circ}$ & Góis & $307^{\circ}$ \\
\hline $78^{\circ}$ & Machico & $188^{\circ}$ \\
\hline $94^{\circ}$ & Ferreira do Zêzere & $306^{\circ}$ \\
\hline $150^{\circ}$ & Penamacor & $304^{\circ}$ \\
\hline $155^{\circ}$ & Vimioso & $119^{\circ}$ \\
\hline $167^{\circ}$ & Cantanhede & $124^{\circ}$ \\
\hline $178^{\circ}$ & Faro & $10^{\circ}$ \\
\hline $232^{\circ}$ & Castelo de Paiva & $277^{\circ}$ \\
\hline $271^{\circ}$ & Palmela & $50^{\circ}$ \\
\hline $297^{\circ}$ & Alcochete & $32^{\circ}$ \\
\hline
\end{tabular}

Quatro dos concelhos presentes no Quadro 3 apresentam uma diferença entre as respectivas posições ocupadas num e noutro ranking superior a 250. À excepção de dois concelhos, as diferenças entre os dois rankings, no Quadro 3, são todas da ordem dos três dígitos.

É importante ressalvar, contudo, que se atendermos à prática de tarifas sociais (que beneficiam determinados cidadãos e agregados carenciados ou numerosos ), a maioria dos concelhos que pratica tarifas desta natureza pertence ao grupo de concelhos onde se pratica um EQME mais elevado. Estas tarifas especiais podem, assim, ser interpretadas como uma eventual forma de compensação aos consumidores pela prática de preços relativamente elevados para quantidades essenciais. No mesmo sentido, a prática de tarifas sociais pode ser lida como uma forma de atender a discrepâncias intra-municipais entre agregados familiares, discriminando positivamente situações de maior vulnerabilidade económica e social.

No que diz respeito à distribuição do rendimento e dos encargos, a Figura 1 apresenta as curvas de concentração respectivas. 


\section{0}

Figura 1 - Distribuição do Rendimento / Distribuição dos encargos com o consumo de água

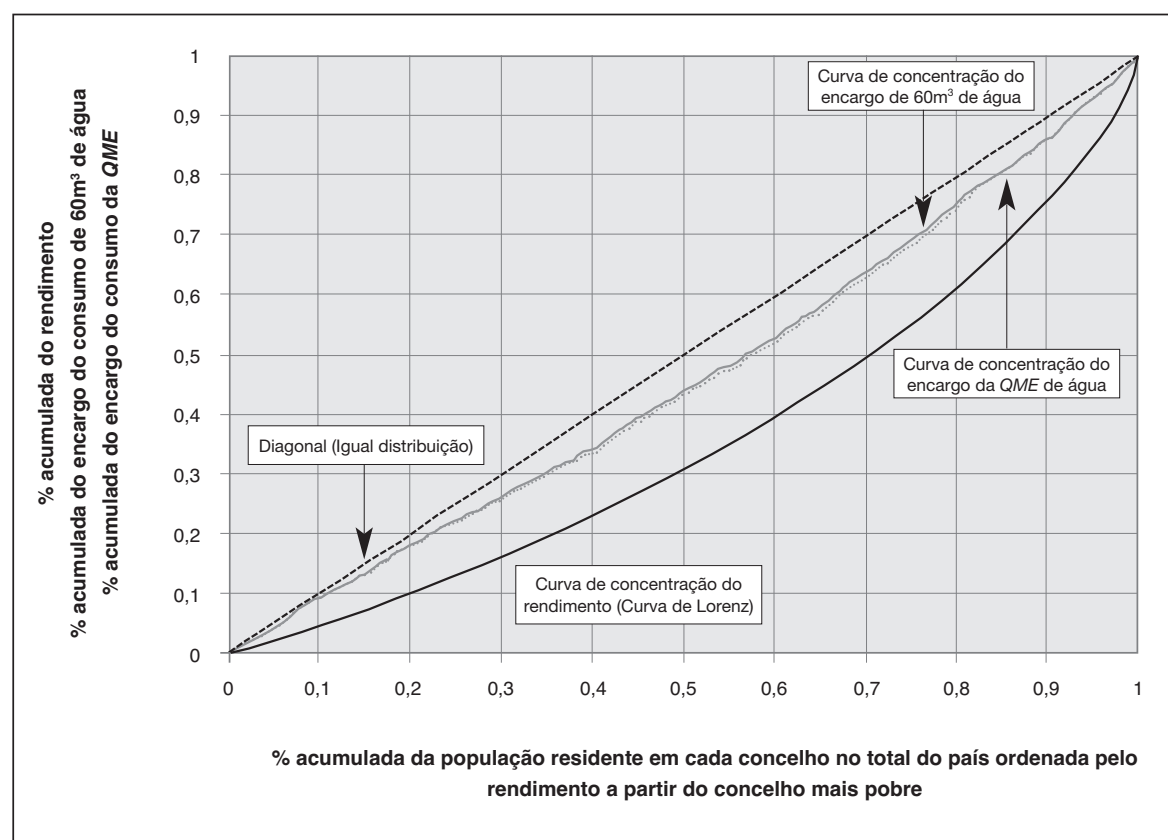

Conforme se pode observar na Figura 1, a curva de Lorenz é a que se encontra mais afastada da diagonal, pelo que das três distribuições ilustradas a do rendimento é a que reflecte uma maior desigualdade. É de notar, contudo, que pelo facto de os rendimentos serem referentes a 2003, e os tarifários utilizados para calcular as séries dos encargos serem de 2007, as curvas não são contemporâneas.

No que concerne às curvas de concentração dos encargos, existe uma quase sobreposição, sendo a dos encargos relativos ao consumo de $60 \mathrm{~m}^{3}$ aquela que mais se aproxima da diagonal.

A não coincidência entre cada uma das curvas de concentração dos encargos e a curva de Lorenz significa que o princípio da capacidade de pagar não está incorporado nas estruturas tarifárias para as quantidades consideradas. $\mathrm{O}$ facto de as duas curvas de concentração dos encargos com o consumo de água situarem-se acima da curva de Lorenz, significa que são as famílias representativas dos concelhos de menor rendimento que destinam uma maior proporção do seu rendimento para este tipo de despesa. Conclui-se, assim, que existe regressividade nos pagamentos, revelando a existência de iniquidade favorável às famílias (concelhos) de rendimentos mais elevados. Embora de forma pouco expressiva, esta regressividade é maior no caso dos encargos associados aos $60 \mathrm{~m}^{3}$ já que o afastamento entre a curva de concentração destes encargos e a curva de Lorenz é ligeiramente maior.

O valor do índice de Kakwani ( $\beta$ da equação (4)), estimado por regressão linear, com recurso ao software gretl, encontra-se no Quadro 4. Este índice assume o valor -0,196 para o caso do EQME e o valor -0,206 para o caso das despesas com o consumo de $60 \mathrm{~m}^{3}$ de água. 


\begin{tabular}{|c|c|c|}
\hline \multicolumn{3}{|l|}{ Para QME } \\
\hline Variável & Constante & Valor $\mathrm{P}$ \\
\hline Constante & 0,098 & $<0,000$ \\
\hline$\beta$ & $-0,196$ & $<0,000$ \\
\hline \multicolumn{3}{|l|}{ Para $60 \mathrm{~m}^{3}$} \\
\hline Variável & Constante & Valor $\mathrm{P}$ \\
\hline Constante & 0,103 & $<0,000$ \\
\hline$\beta$ & $-0,206$ & $<0,000$ \\
\hline
\end{tabular}

Um primeiro resultado a salientar é o facto do coeficiente $\beta$ (ou seja, $\Pi_{K}$ ) ser estatisticamente diferente de zero nos dois casos. Está assim excluída a hipótese de proporcionalidade dos encargos com o consumo de água face ao rendimento. Em segundo lugar, confirma-se os valores negativos para $\Pi_{K}$ e a semelhança entre os coeficientes para as duas quantidades consideradas, como esperado face à quase sobreposição das curvas de concentração respectivas.

É de referir ainda que, apesar da prática generalizada de TPC, as quais são tendencialmente progressivas (sob a hipótese de que consumos mais elevados estão associados a rendimentos também mais elevados), o encargo com o consumo de água inclui uma componente fixa (EF). Sendo esta última componente independente do consumo, logo do rendimento, trata-se de uma forma de pagamento regressiva. Os resultados no Quadro 4 podem reflectir em parte a combinação destes dois efeitos.

\section{Conclusão}

Com o presente estudo pretendia-se avaliar em que medida estão a ser tidas em conta preocupações de equidade na definição e aplicação dos tarifários de serviços de abastecimento de água ao segmento residencial nos concelhos portugueses.

Em termos das quantidades mínimas essenciais, o papel do primeiro escalão de consumo, tal como sugerido pela literatura, no sentido de acomodar essas quantidades, parece pouco compatível com os tarifários praticados em Portugal, por defeito e por excesso. Isto é, tanto se encontram casos em que a QME não está totalmente coberta pelo primeiro bloco de consumo, como se encontram casos em que o primeiro bloco excede consideravelmente a $Q M E$.

Da análise comparativa entre os encargos associados ao consumo de água e o rendimento médio da família representativa de cada concelho, conclui-se pela existência de grandes disparidades em termos das posições ocupadas por cada concelho nos rankings de encargos e rendimentos. A elaboração de curvas de concentração e o cálculo do índice de Kakwani confirmou a suspeita, gerada pela análise de rankings, de que não se verifica o princípio da capacidade de pagar nos tarifários, em Portugal. Os encargos, quer para a $Q M E$, quer para $60 \mathrm{~m}^{3}$ de consumo anual, revelaram-se regressivos.

Assim, em resposta à questão formulada no título, neste trabalho não se consegue explicar os TPC com base em justificações de equidade, tal como estudos anteriores para o mesmo contexto (Roseta-Palma e Monteiro, 2008) não conseguiram justificar os tarifários com base em argumentos de eficiência e de escassez do recurso.

Naturalmente, da perspectiva de equidade, interessaria também averiguar o respeito pelo princípio da capacidade de pagar dentro de cada concelho. Havendo disponibilidade de dados, 
este poderá ser um dos passos seguintes da investigação aqui relatada. Outra via a explorar de futuro consiste na identificação da localização geográfica dos concelhos com maiores disparidades entre os dois rankings aqui analisados, de modo a tentar perceber-se se outras lógicas, tais como a disponibilidade do recurso natural ou a densidade populacional, subjazem às aparentes contradições por nós encontradas.

$\mathrm{Na}$ realidade, qualquer tarifário adoptado tem de lidar com conflitos de objectivos e, mais ainda, com a questão sobre se deve preponderar uma lógica de regras de mercado ou se deve ser a garantia do acesso ao serviço (pela sua natureza vital) a presidir à formação do preço. Provavelmente, os tarifários acabam por nunca reflectir uma das lógicas isoladamente. 


\section{Referências Bibliográficas}

Arbués, Fernando et al. (2003) Estimation of residential water demand: a state-of-the-art review, Journal of Socioeconomics, 32, 8-102.

Bolland, John; Whittington, Dale (2000) "The political of water tariff design in developing countries: increasing block versus uniform price with rebate", in Dinar, Ariel (ed.), The Political Economy of Water Pricing Reforms, New York, Oxford University Press, 215-235.

Buchanan, Allen (1985) Ethics, efficiency, and the market, Oxford, Clarendon Press.

Griffin, Ronald (2007) Water Resources Economics, The Analysis of Scarcity, Policies, and Projects, Massachusetts, The MIT Press Cambridge.

Hirshleifer, Jack et al. (1960) Water Supply: Economics Technology and Policy, Chicago, University of Chicago Press.

INE (2009) Dados estatísticos - Base de dados-Tema: População - Subtema - Censos da População - Indicador: Famílias clássicas $\left({ }^{\circ} .^{\circ}\right.$ ) por Local de residência e Dimensão (familia clássica) - Âmbito geográfico: Portugal, disponível em http://www.ine.pt.

IRAR (2008) Relatório Anual do Sector de Águas e Resíduos em Portugal - RASARP (2007), Volume 1 - Caracterização geral do sector, IRAR.

Kakwani, Nanak et al. (1997) Socioeconomic inequalities in health: Measurement and statistical inference, Journal of Econometrics, 77 (1), 87-104.

Monteiro, Henrique (2005) Water pricing Models: a survey, WP 2005/45, Dinâmia - Centro de Estudos sobre a Mudança Socioeconómica, Lisboa, Instituto Superior de Ciências do Trabalho e da Empresa.

OECD (2009) Managing Water for All, An OCDE perspective on pricing and Financing, Paris, OECD.

OECD (2003) Social Issues in the Provision and Pricing of Water Services, Paris, OECD.

Roseta-Palma, Catarina; Monteiro, Henrique (2008) Pricing for scarcity, Working Paper 2008/65, Dinâmia, Lisboa, ISCTE.

Wagstaff, Adam; van Doorslaer, Eddy (2000) Equity in health care finance and delivery in Culyer, Anthony; Newhouse, Joseph (eds.), Handbook of health economics, Amesterdam, Elsevier, 1803-1862. 